\title{
УДК 334.716:005.591.4
}

DOI: 10.15587/2313-8416.2018.124433

\section{ТЕОРЕТИКО-МЕТОДОЛОГИЧЕСКИЕ АСПЕКТЫ ТРАНСФОРМАЦИОННЫХ ПРО- ЦЕССОВ В ЭКОНОМИЧЕСКОЙ СФЕРЕ ДЕЯТЕЛЬНОСТИ ПРОМЫШЛЕННЫХ ПРЕДПРИЯТИЙ}

\author{
(C) Е. А. Плахотник
}

Проведен анализ факторов экономического развития национальной экономики, что позволяет установить приоритетное значение институционализма для понимания экономического развития, которое состоит в возможности объединения экономических прочессов и сочиально-экономических, политических и культурных изменений. Разработана концепция развития трансформационных процессов в экономической сфере деятельности промышленных предприятия на основе комплексного системного подхода Ключевые слова: трансформационные прочессы, промышленные предприятия, экономическая сфера деятельности, концепция, институциональные изменения

\section{1. Введение}

Современная глобализация мировой экономики существенно влияет на развитие экономической системы Украины в целом и отдельных ее секторов. Стратегически важной задачей становится необходимость обеспечения условий эффективного регулирования экономических отношений, определения оптимальной структуры национальной экономики, на основе реформирования системы институтов, которые будут способствовать росту и эффективному использованию ресурсного потенциала государства, повышению его инвестиционного рейтинга и усилению конкурентных позиций в мировой экономике.

Переход Украины к инновационной модели развития выступает условием активизации трансформационных процессов в экономической сфере функционирования предприятий всех секторов экономики, формирования эффективной политики государственного регулирования экономики. Однако, в течение переходного периода сохраняются негативные проявления рыночных деформаций - коррумпированность и тенизация экономики, нестабильность национальной валюты, высокая стоимость топливно-энергетических ресурсов, низкая активность долгосрочного кредитования промышленного сектора и т. д. При таких условиях жизнедеятельность субъектов хозяйствования в значительной мере зависит от внедрения новейших концепций управления, важное место среди которых занимают трансформационные процессы в экономической сфере деятельности промышленных предприятий.

\section{2. Анализ литературных данных и поста- новка проблемы \\ На сегодняшний день в отечественной и зару-} бежной экономической литературе активное методологическое, методическое и научно-практическое изучение получили вопросы исследования трансформационных процессов в экономике $[1,2]$. Большое внимание уделяется определению места и роли промышленных предприятий в процессах рыночной трансформации экономики Украины [3, 4]. Значительный вклад вносится и в обоснование направлений формирования рациональных и эффективных институциональных структур национальной экономики [5], совершенствования направлений увеличе- ния ВВП Украины при различных проявлениях факторов внешней среды $[1,4]$. Однако, несмотря на наличие значительного количества монументальных исследований трансформационных процессов развития экономики Украины, вопросы концептуального обоснования влияния экономической сферы деятельности промышленных предприятий на трансформационные изменения соответствующих институтов и институций на сегодняшний день отсутствуют.

\section{3. Цель и задачи исследования}

Целью данной статьи является изучение на институциональном подходе и принципах системного развития с определением предприятия как институции концептуальных основ развития трансформационных процессов в экономической сфере их деятельности, что позволит определить ключевые задачи повышения эффективности функционирования рыночной экономики.

Для достижения цели были поставлены следующие задачи:

1. Провести ретроспективный анализ трансформации институционального сектора экономики Украины.

2. Обосновать принципы формирования системы экономического развития государства в целом и его промышленных предприятий в частности.

3. Разработать концепцию развития трансформационных процессов в экономической сфере деятельности промышленных предприятий.

4. Исследование трансформационных процессов в экономической сфере деятельности промышленных предприятий и страны в целом

Переход экономики Украины от плановодирективной к рыночной модели не сопровождался изменением институтов и институций, что привело к дисбалансу развития базовых секторов экономики. Как правило, естественный процесс развития экономики предполагает преобразование институтов и институций по мере развития и изменения развития общества, экономики, что было доказано на исследовательском уровне $[1,2]$.

Первый период рыночных преобразований (1985-1991 гг.) сопровождался ростом экономики. 
Именно в это время население поддерживало провозглашенные лозунги разгосударствления экономики, формирования частной трудовой собственности, демократизации общества. Однако, были получены иные результаты, началось формирование крупной нетрудовой частной собственности, разрушение государственности, обнищание населения. Это привело к тому, что к середине 90-х годов ВВП Украины снизился более чем на $50 \%$, а промышленность - почти на $60 \%$. В этот период удельный вес сырьевых отраслей и производств 1-3-го технологических укладов в экономике значительно увеличился, а состояние развития науки 4-5-го технологических укладов резко упало.

Системный социально-экономический кризис, достигнув своего максимального уровня, сменился некоторым оживлением, а рост экономических показателей Украины (2000-2004 гг.) был использован политиками и их «научным» окружением в утверждениях о преодолении кризиса, быстром росте, «европейском (украинском) экономическом чуде». Однако, еще тогда многие ученые отмечали, что имеет место неустойчивый рост, а подъем на завершающей фазе экономического кризиса, который не обеспечивает стабильность ввиду отсутствия системной модели экономического развития [6]. Показатели экономического развития Украины в 2005 г. были такими: ВВП вырос на 2,7 \%. В августе 2005 г. впервые за последние шесть лет произошло его абсолютное снижение по сравнению с аналогичным периодом (августа) 2004 г. Промышленное производство за январьдекабрь 2005 г. выросло на 3,1\%, что ниже уровня соответствующего периода 2004 г. более чем в четыре раза (за 2004 г.) [7].

В 2005 г. наблюдались попытки силового передела собственности. По всей стране готовились к рассмотрению тысячи дел по пересмотру прав собственности. Речь идет не о «Криворожстали», Северодонецком химкомбинате «Азот» и т. д., а о парикмахерских, небольших заводах, мастерских. Попытки передела собственности наблюдаются и в 20062007 гг., о чем свидетельствует так называемое «рейдерство» [8]. После спада экономики в 2005 г. и в начале 2006 г., практически со второго полугодия 2006 г., начался подъем. По итогам 2006 г. ВВП возрос к уровню 2005 г. на $7 \%$, плановые бюджетные показатели выполнены на 104,7 \% (в 2005 г. - 99,3\%), рост бюджета к уровню 2005 г. составил 27 \%. Номинальные доходы населения возросли на 28,2 \% при инфляции 11,6 \%. По решению организации экономического содружества и развития Украина переведена из 6 в 5 группу экспортных кредитных рисков [7].

После мощнейшего падения экономики Украины в 2014-2015 гг. рост ВВП Украины в 2016 году на 1,5 \% является положительным сигналом к увеличению инвестиционной привлекательности государства и его конкурентоспособности. Данный прирост ВВП был обусловлен улучшением внешней конъюнктуры на металлургическом рынке (рост цен на сталь) и рекордным урожаем зерновых. Однако, для того, чтобы догнать по уровню ВВП на душу населения хотя бы страны Восточной Европы, Украине нужно обеспечивать на протяжении около двух десятков лет ежегодный рост ВВП не меньше, чем на 7-8 \%.

Проанализируем нынешнее состояние экономики Украины по таким индикаторам как рейтинг благоприятности деловой среды, рейтинг процветающих стран мира, рейтинг свободных экономик. Так, по состоянию на июнь 2017 г. Украина по рейтингу благоприятности деловой среды (Doing Business2017), который ежегодно составляет Всемирный банк (ВБ) и Международная финансовая корпорация (IFC) по сравнению, например, с 2015 г., улучшила свой результат на 20 позиций и переместилась с 96-го на 76-е место (из 190 позиций). Составители рейтинга констатируют, что Украина «продемонстрировала значительные улучшения в облегчении ведения бизнеса за последний год» [9].

В рейтинге процветающих стран мира, традиционно составляемом лондонским Legatum Institute в 2017 году среди 149 стран Украина получила 112-ое место. Перед Украиной - Ботсвана, Индия, Кения, а следом - Зимбабве, Эфиопия, Центрально - Африканская Республика. Лидерские позиции рейтинга традиционно заняли Норвегия, Швейцария, Швеция. В первую десятку не попали США, заняв только 18 место. Данный рейтинг оценивает 9 параметров мощь экономики, деловой климат, эффективность управления, систему образования, уровень здравоохранения, безопасность, личная свобода человека, социальный капитал, экология [10].

В рейтинге свободных экономик Heritage Foundation и изданием The Wall Street Journal в 2016 г. Украина занимает 162 позицию. Странами с самыми свободными экономиками, как и год назад, признаны Гонконг, Сингапур и Новая Зеландия, а несвободными - Венесуэла, Куба и КНДР. США заняли в рейтинге 11-ю позицию. В рейтинге Украина сохранила ту же позицию, что и год назад - в самом конце группы стран с «преимущественно несвободной» экономикой. Кроме того, к этой категории составители рейтинга отнесли Узбекистан и Туркменистан [10].

В 2017 г. несвободными, или подавленными, названы экономики 23 стран, в том числе и экономика Украины. В рейтинге экономических свобод Украина заняла 166-е место из 180 стран, потеряв за год четыре позиции. В нынешнем рейтинге Украина оказалась между Анголой и Суринамом. Ближайшего географического соседа от Украины отделяют 52 позиции. Экономика Украины сократилась и остается очень хрупкой. «Постоянные разрушения производственных и экспортных мощностей и значительный отток капитала страны усилили давление на валюты и резервы, существенно подорвав денежную стабильность» [11]. Общая устойчивость финансовой политики значительно ухудшилась, и резко возрос дефицит государственного бюджета и долга, утверждают исследователи. При этом они отмечают слабость верховенства закона и судебную неэффективность. Украинская экономика страдает от отсутствия достаточной капитализации, а большое количество необслуживаемых кредитов тормозит банковскую систему.

Весьма неутешительными являются дополнительные индикаторы, полученные Всемирным 
экономическим форумом, которые используются для характеристики возможностей роста конкурентоспособности Украины. Согласно отчету о глобальной конкурентоспособности Global Competitiveness Index 2016-2017 гг. Украина потеряла шесть позиций, переместившись с 79 на 85 место из 138 стран. Ступенькой выше оказалась Намибия (84 место), ниже - Греция (86 позиция). Ближайшие географические соседи Украины заняли в рейтинге следующие места: Россия - 43, Молдова - 100, Румыния - 62, Польша - 36 [12].

Самые большие проблемы в Украине - коррупция, политическая нестабильность, качество институтов и финансового рынка. Также негативно отражаются на конкурентоспособности инфляция, правительственная бюрократия и доступ к финансированию. Из 12 показателей самыми слабыми, согласно исследованию [13], оказались развитие финансовых рынков (130 место), развитие институтов (129 место), макроэкономическое окружение (128 место) и эффективность товарных рынков (180 позиция в рейтинге).
Исследователи [13], отнесли Украину к группе стран, которая переходит от первой стадии (factor driven - драйвером развития конкурентоспособности являются производственне ресурсы) ко второй стадии (efficiency driven - эффективно развивающаяся экономика). Третья стадия - innovation driven, то есть развития с помощью инноваций, для Украины, к сожалению, пока недоступна.

Таким образом, теоретико - методологические основы развития экономики обусловливают потребность в создании эффективной системы управления трансформационными процессами в экономике Украины.

\section{5. Результаты исследования}

Исходя из изложенного выше, а также опираясь на исследование подходов к управлению экономическими, социальными и политическими трансформациями предложим следующие принципы формирования системы экономического развития государства в целом и его промышленных предприятий в частности (рис. 1).

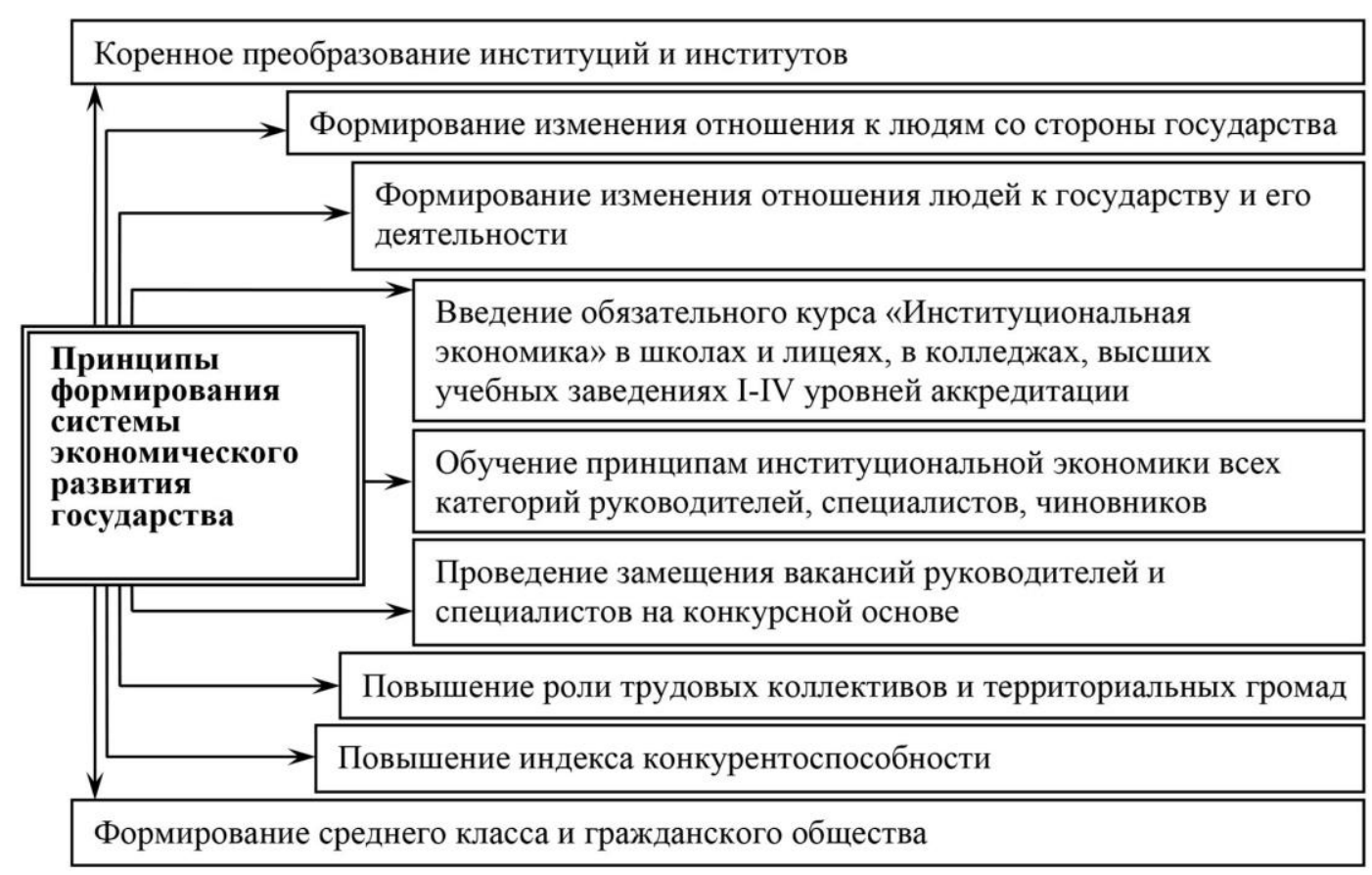

Рис. 1. Принципы формирования системы экономического развития государства

Современная трансформация является слишком глобальной для того, чтобы определять наступающее общественное устройство как посткапиталистический строй [14]. Происходящие перемены затрагивают уже не индустриальную форму хозяйства, а саму природу человеческой деятельности, структуру и характер предпочтений и ценностей индивида. Исходя из этого, выделяется две глобальные эпохи [14]:

- первая - эпоха, которая ознаменовала становление общества, и на ее протяжении поведение человека обусловливалось реальными потребностями вполне непосредственно и прямо; люди противостояли силам природы как единый организм, их объединяли примитивные инстинкты самосохранения и выживания;
- вторая - эпоха, в которой люди стали осознавать себя представителями определенного класса или общественной группы, занимающими заданное место в социальной иерархии или общественном производстве.

Имеет место разделение труда, обмен и распределение на принципах частной собственности, эксплуатация одной части общества другой. Индивиды осознают свои материальные интересы как отличные от интересов других и общества в целом. Это характерно для различных форм - от античного полисного хозяйства до капиталистического производства.

Совершенствование технологических основ общественного производства не может быть адекват- 
ной основой вычленения периодов исторического развития, ибо этот поступательный процесс обеспечивает лишь череду последовательных успехов человеческого рода в постоянном возрастании власти над природой; а также нельзя признать адекватным и подход к истории цивилизации как к смене отдельных социальных форм, каждая из которых считается завершенным и самодостаточным целым [14].

Сегодня основными факторами производства становятся информация и знания, и стремление человека к материальному богатству или достижению высокого социального статуса не может заменить потребности в развитии собственной личности, в умножении своих умений и способностей. С каждым следующим поколением новая система мотивации принимается все более широким кругом людей, и нематериальные интересы становятся доминантой социального развития. Это и есть третья эпоха.

В настоящее время (с 90-х годов ХХ ст.), по мнению многих экономистов, происходит переход от индустриального общества к постиндустриальному, которому характерны массовое распространение творческого, интеллектуального труда, возросший объем научного знания и информации, преобладание в экономике сферы услуг, науки, образования, культуры над промышленностью. При этом все больше научные поиски сосредотачиваются на изучении таких важных проблем, как сущность постиндустриальной организации, ее структурных элементов и их соотношения, технико-технологических и социальноэкономических параметров и т. п.

Исследования ученых, связанные с проблемами экономического развития национальной экономики, актуализировались в связи с имевшим место спадом в экономике Украины (2005 - начало 2006 г.), ее ростом с середины 2006 г., когда увеличился темп роста ВВП и промышленной продукции, а также существенным спадом экономики в 2014 г. Появились работы, в которых экономический рост в Украине рассматривается как уже состоявшееся явление, требующее государственного регулирования. Однако, более глубокий анализ экономических, социальных, институциональных проблем, переживаемых украинским обществом, свидетельствует о преждевременности подобных выводов и требует более детального обоснования. В настоящее время резко возрастает потребность в глубокой дальнейшей разработке методологических проблем экономической науки и ее концепций. Требуется приложить немало усилий и на то, чтобы понять, в чем состоят главные проблемы, каковы условия их возникновения и методы решения. Всестороннее осознание проблем способно консолидировать ученых, специалистов, практиков, представителей власти, а затем и все общество для обеспечения экономического роста.

Как отмечают специалисты, сегодня общепризнано существование 6-ти технологических укладов $[4,14]$. В настоящее время в развитых странах доминируют технологии 5-го и формируются технологии 6-го технологических укладов. Начало 5-го уклада связывают с развитием новых средств коммуникации, цифровых сетей, компьютерных программ и генной инженерии. Этот уклад активно генерирует создание и непрерывное совершенствование как но- вых машин и оборудования, так и информационных систем. Возрастает роль природного газа и нетрадиционных источников энергии. Для 6-го технологического уклада ключевыми направлениями являются: биотехнология, системы искусственного интеллекта, CALS-технологии, глобальные информационные сети и интегрированные высокоскоростные транспортные системы, компьютерное образование, формирование сетевых бизнес-сообществ. Развитие этих отраслей в ведущих странах мира имеет темпы прироста $20-100 \%$ в год.

В центре внимания 5-го и 6-го укладов находится уровень развития науки, инновационной инфраструктуры, человека как носителя знаний и передового производственного опыта. Поэтому экономику даже высокоразвитых стран можно относить к трансформационной, а для ее изучения недостаточно традиционных методов исследования. Наряду с методами классической экономической теории необходимо использовать методы институциональной экономической теории, которая рассматривает информацию как ограниченный ресурс, имеющий свою цену, институты государства и гражданского общества, как важные факторы развития экономики, общества, человека.

Уже в настоящее время в экономике развитых стран наблюдается устойчивый рост сферы услуг, обеспечивающей более 50 \% ВВП. Растут нематериальные активы предприятий, знания становятся товаром, получает юридическо-правовое обеспечение интеллектуальный капитал. Одновременно при абсолютном росте снижается удельный вес сферы материального производства, промышленности в производстве ВВП.

Отечественные исследователи, анализируя противоречивые последствия глобализации и регионализации для различных государств, приходят к вполне аргументированным выводам, что глобальные процессы все плотнее пересекаются с базовыми аспектами внутреннего развития отдельных стран, быстро расширяют и углубляют свое влияние на него. Для развитых государств (наций) этот процесс является естественным, тогда как для остальных - в лучшем случае противоречивым, а преимущественно - болезненным или даже разрушительным. Речь идет не об экономическом развитии как таковом, тем более не об уровне доходов на душу населения, а прежде всего об общественно-политическом развитии нации и гражданских качествах населения определенной страны. Указанные параметры национального развития - ключевые для определения потенциала национальной успешности и возможностей участвовать в интернациональных процессах. Вполне вероятно, что многим нациям, задержавшимся в своем развитии, не хватает исторического времени для повторения классического пути становления и консолидации. А развитие вдогонку - это не только и не столько технологические заимствования, а прежде всего внедрение современных норм организации общественно-политической жизни $[1,2]$.

Исследование трансформационных процессов в экономической сфере деятельности промышленных предприятий Украины, складывающихся под влия- 
нием экономических, политических и социальных преобразований, позволило разработать на основе комплексного системного подхода концепцию их развития (рис. 2).

Таким образом, рассматривая экономический рост как критерий экономического развития национальной экономики, следует отметить, что если экономический рост происходит при увеличении таких факторов как экономическое неравенство, ущемле- ние демократии, отсутствие прогресса в области развития человека, то такое экономическое развитие является неустойчивым.

Для приобретения устойчивости экономического развития экономический рост должен сопровождаться такими факторами как увеличение знаний и умений человека, т. е. человеческого капитала, наряду с возможностью их эффективного использования - улучшения качества жизни.

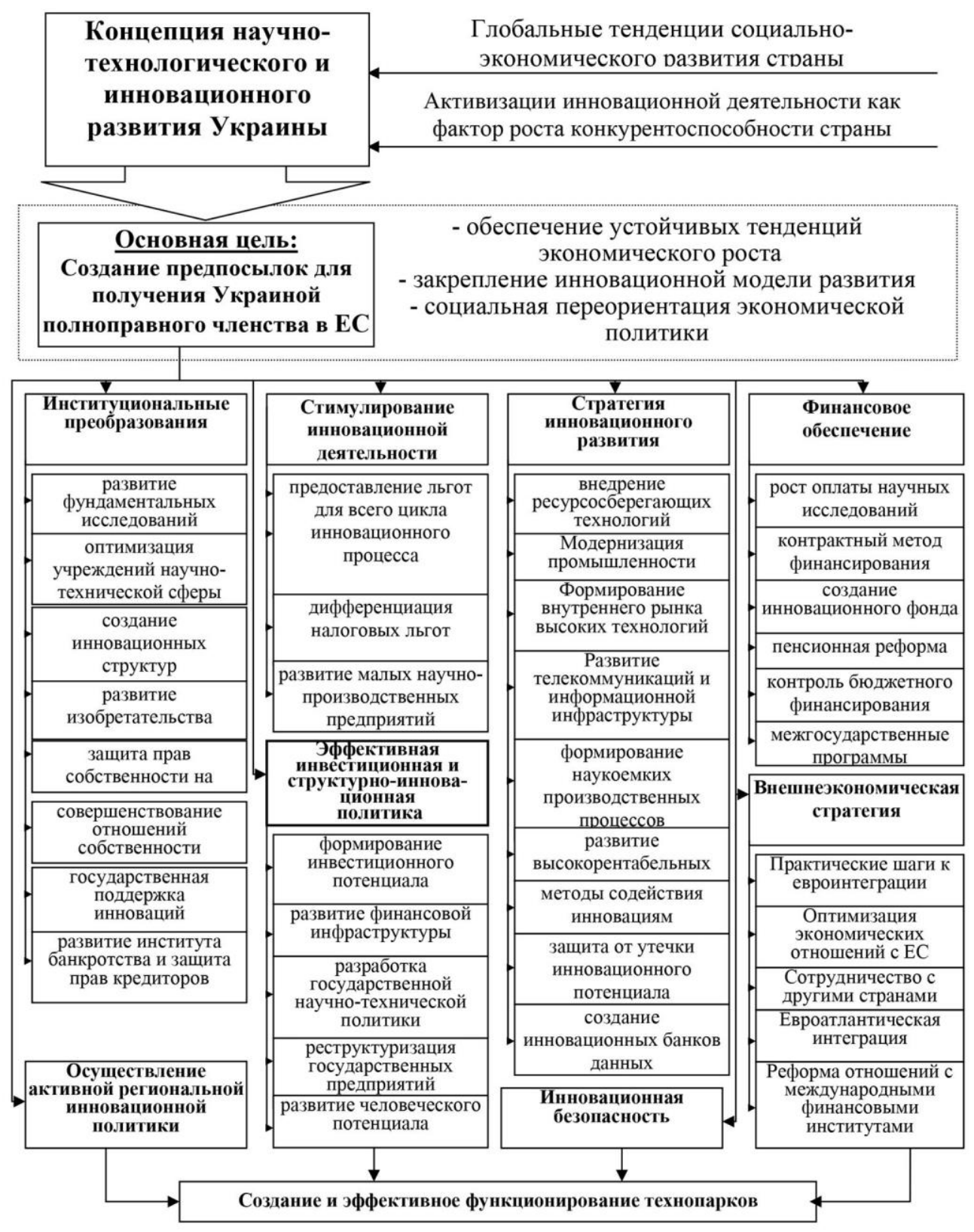

Рис. 2. Концепция развития трансформационных процессов в экономической сфере деятельности промышленных предприятий

Изменение структуры экономики невозможно без институциональных изменений в Украине. Однако новые институты рыночной экономики являются формальными и в силу различных причин не реализуются ни населением, ни властными структурами, что в свою очередь оказывает отрицательное влияние на состояние экономической системы, поскольку такая система не в состоянии осуществлять устойчивое экономическое развитие. Следовательно, для осуществления устойчивого экономического развития национальной экономики Украины необходимо реформирование институтов путем углубления институциональных реформ.

Необходимо отметить, что в основу формирования концепции развития трансформационных процессов в экономической сфере деятельности про- 
мышленных предприятий положены принципы:

- комплексности и системности;

- институциональных преобразований;

- стимулирования инноваций;

- стратегического инновационного развития;

- непрерывности развития;

- гибкости и адаптивности.

Анализ факторов экономического развития национальной экономики позволяет установить приоритетное значение институционализма для понимания экономического развития, которое состоит в возможности объединения экономических процессов и социально-экономических, политических и культурных изменений. Поскольку институты определяют поведение экономических субъектов, то институциональные изменения предшествуют структурным изменениям в экономике.

\section{6. Выводы}

1. Проведенный ретроспективный анализ трансформации институционального сектора экономики Украины показал, что на всех этапах перехода экономики от планово-директивной к рыночной, отсутствовали объективно-необходимые преобразования институтов и институций. Это явилось основной проблемой обеспечения устойчивого экономического роста Украины и главным фактором сдерживания реформ. В качестве основных проблем институционального сектора в Украине идентифицируются коррупция, политическая нестабильность, качество самих институтов и эффективность рынков, правительственная бюрократия.

2. В качестве основных принципов формирования системы экономического развития государства выделены:
- коренное преобразование институций и институтов;

- формирование изменения отношения к людям со стороны государства;

- формирование изменения отношений людей к государству и его деятельности;

- введение в систему школьного и высшего образования дисциплины «Институциональная экономика»;

- обучение принципам институциональной экономики всех категорий руководителей, специалистов, чиновников;

- проведение замещения вакансий руководителей и специалистов на конкурсной основе;

- повышение роли трудовых коллективов и территориальных громад;

- увеличение индекса конкурентоспособности, формирование среднего класса и гражданского общества.

3. Основной целью разработанной концепции развития трансформационных процессов в экономической сфере деятельности промышленных предприятий является получение Украиной полноправного членства в ЕС путем обеспечения устойчивых тенденций экономического роста, закрепления инновационной модели развития и формирование социальных приоритетов экономической политики.

Достижение указанной цели предполагает в качестве основных направлений реализации данной концепции стимулирование инновационной деятельности, осуществление институциональных преобразований, разработку внешнеэкономической стратегии, осуществление активной региональной инвестиционной политики и т. д.

\section{Литература}

1. Чухно А. А. Модернізація економіки та економічна теорія // Економіка України. 2012. № 9. С. 4-12.

2. Геец В. М. Общество, государство и экономика: единство и противоречия. Москва: Ин-т экономики, 2012.67 с.

3. Геєць В. М. Економіка України: ключові проблеми і перспективи // Економіка і прогнозування. 2016. № 1. С. 7-22.

4. Трансформаційні процеси економічної системи в умовах сучасних викликів: монографія / за ред. В. І. Гринчуцького. Тернопіль: Крок, 2014. 544 с.

5. Войнаренко М. П. Кластери в інституційній економіці: монографія. Хмельницький: ХНУ, Тріада-М, 2011. 502 с.

6. Украина и ее регионы на пути к инновационному обществу. Т. 4: монография / Амоша А. И., Булеев И. П., Дубницкий В. И. и др. Донецк: Юго- Восток, 2011. 372 с.

7. Економіка України за 2006 рік // Урядовий кур'єр. 2007. № 15. С. 1-6.

8. Підприємців учать відбиватися від рейдерів // Урядовий кур’єр. 2007. № 34. С. 3.

9. Рейтинг стран 2017. URL: http://russian.doingbusiness.org/rankings

10. Какое место заняла Украина в рейтинге свободных экономик от Heritage Foundation. URL: http://yкроп.org/kakoemesto-zanyala-ukraina-v-rejtinge

11. Инфографика: Рейтинг экономических свобод: Украина между Анголой и Суринамом. URL: http://www.liga.net/ infografica/318571_reyting-ekonomicheskikh-svobod-ukraina-mezhdu-angoloy-i-surinamom-.htm

12. Всемирный экономический форум: рейтинг глобальной конкурентоспособности 2016-2017. URL: http://gtmarket.ru/ news/2016/09/28/7304

13. Инфографика: Рейтинг конкурентоспособности: Украина потеряла шесть позиций. URL: http://www.liga.net/ infografica/314707_reyting-konkurentosposobnosti-2017-ukraina-poteryala-shest-pozitsiy.htm

14. Иноземцев В. Л. Что случилось с Россией. Москва: Алгоритм, 2015. 255 с.

Дата надходження рукопису 18.01.2018

Плахотник Елена Александровна, доктор экономических наук, профессор, заведующий кафедрой, Кафедра экономики и организации производства, Днепровский государственный технический университет, ул. Днепростроевская, 2, г. Камянское, Украина, 51918

E-mail: plahotnik_elena@ua.fm 